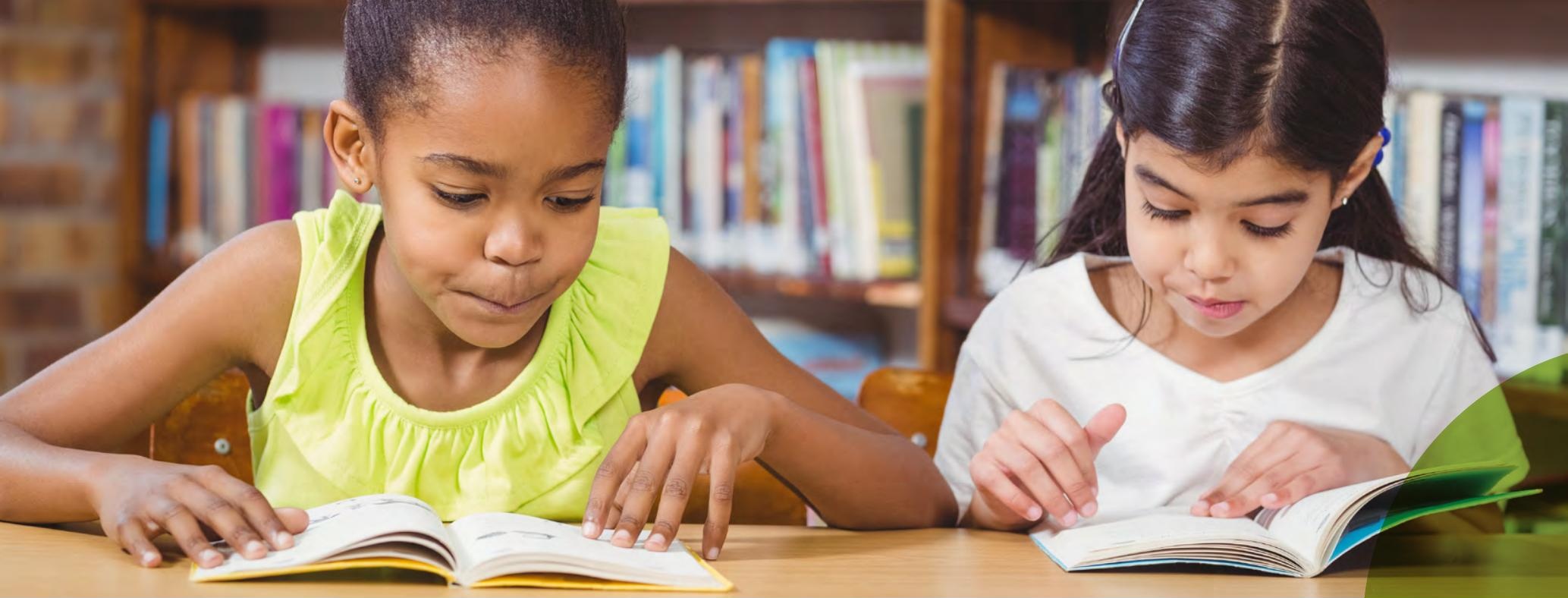

\title{
Early deprivation is linked to long-term social communication difficulties
}

\section{By Dr. Jessica K Edwards}

Maltreatment affects a staggering 1 billion children worldwide. ${ }^{1}$ Most of these maltreated children, but particularly those raised in institutions that are characterized by deprivation, experience some form of neglect. These children seem to be at risk of developing social, cognitive and psychiatric difficulties later in life. ${ }^{2}$

In a longitudinal, randomized controlled trial, Mark Wade and colleagues examined the long-term consequences of institutional rearing on social communication. In this study named the Bucharest Early Intervention Project, children reared in Romanian institutions were randomly assigned to care-as-usual (remaining in institutions) or high-quality foster care in early childhood. A matched group of never institutionalized children was also recruited. Then, participants were followed up in childhood and adolescence and assessed for social communication difficulties and psychopathology.

Consistent with previous studies, ${ }^{2}$ the researchers found that children reared in an institution had more social communication problems at age 16 than children who had never been institutionalized. Those placed into foster care early in life exhibited fewer problems with reciprocal social interaction compared to those who remained in institutions. Early placement into a socially enriched environment, therefore, seems to mitigate the risk of developing problems in this domain of social communication.

Wade et al. also assessed the associations between social communication and psychopathology from age 8 to 16 years. Here, they found that poor social communication at age 8 was linked with general psychopathology at age 16 . What's more, social communication deficits at age 8 partially mediated the effects of institutional rearing on general psychopathology at age 16 . As such, the researchers consider that social communication might serve as a target for early intervention to safeguard institutionalized children against later psychiatric problems.
Referring to:

Wade, M., Zeanah, C.H., Fox, N.A. \& Nelson, C.A. (2020), Social communication deficits following early-life deprivation and relation to psychopathology: a randomized clinical trial of foster care. J. Child Psychol. Psychiatr. doi: 10.1111/ jcpp.13222.

\section{References:}

${ }^{1}$ Hillis, S. et al. (2016). Global prevalence of past-year violence against children: A systematic review and minimum estimates. Pediatrics. 137: e20154079. doi: 10.1542/peds.2015-4079.

${ }^{2}$ Sonuga-Barke, E.J. et al. (2017). Child-to adult neurodevelopmental and mental health trajectories after early life deprivation: the young adult follow-up of the longitudinal English and Romanian Adoptees study. Lancet. 389: 1539-1548. doi: 10.1016/So140-6736(17)30045-4. 